\title{
Electrochemical Regeneration of Various Graphitic Adsorbents in an Air Agitated Sequential Batch Reactor
}

\author{
S. N. Hussain ${ }^{1, *}$, H.M.A. Asghar ${ }^{1}$, H. Sattar ${ }^{1}$, N.W. Brown ${ }^{2}$, E. P. L. Roberts ${ }^{3}$ \\ ${ }^{1}$ Institute of Chemical Engineering and Technology, University of the Punjab, Lahore, Pakistan \\ ${ }^{2}$ Arvia Technology Ltd, United Kingdom \\ ${ }^{3}$ Department of Petroleum and Chemical Engineering, University of Calgary, Canada \\ *Corresponding author: hussain_nadir@hotmail.com
}

Received June 16, 2014; Revised July 02, 2014; Accepted July 10, 2014

\begin{abstract}
With the aim to address the issues related to the regeneration of activated carbon used for wastewater treatment, a novel and state of the art water treatment technology (Arvia) was introduced at the University of Manchester, UK. This technology employs the adsorption of dissolved toxic pollutants present in water onto the surface of graphitic adsorbents followed by their quick and cheap electrochemical regeneration in a simple electrochemical reactor. The main mechanism of regeneration is based on the anodic oxidation of adsorbed species at the adsorbent surface. The adsorbed species are thought to be completely mineralized. However, some of the adsorbed organic contaminants may lead to the generation of toxic intermediate breakdown species owing to incomplete mineralization and/or indirect oxidation of organics present in solution. The former phenomenon may also depend upon the adsorption capacity of the adsorbent to be used. In this paper, a range of graphitic adsorbents including graphite intercalation compound-bisulphate (GIC-bisulpahte), recycled vein graphite (RVG) and exfoliated graphite (EG) were selected so as to investigate the formation of breakdown products during their electrochemical regeneration. Relatively fewer quantities of breakdown products in terms of p-benzoquinone and 4chlorophenol were observed for EG. However, higher concentrations of oxalic acid were found for EG in comparison to GIC-bisulphate and RVG leading to conclude that the electrochemical degradation of phenol at the surface of exfoliated graphite could be through the direct oxidation of phenol into carboxylic acids.
\end{abstract}

Keywords: adsorption, electrochemical regeneration, breakdown products, graphitic adsorbents

Cite This Article: S. N. Hussain, H.M.A. Asghar, H. Sattar, N.W. Brown, and E. P. L. Roberts, "Electrochemical Regeneration of Various Graphitic Adsorbents in an Air Agitated Sequential Batch Reactor." Chemical Engineering and Science, vol. 2, no. 2 (2014): 24-29. doi: 10.12691/ces-2-2-3.

\section{Introduction}

Stringent environmental legislations have forced the industries to reduce the concentrations of toxic organic species in their discharge effluents. Biodegradation is the most cost effective process for the removal of organics from wastewaters. However, the process is not viable for non-biodegradable and toxic species present in water. Therefore a range of physical and/or chemical techniques are used. These include chemical/advanced chemical and electrochemical oxidation, membrane processes and adsorption. Among all these processes, adsorption has been widely used for the removal of organic contaminants from water. The most significant adsorbent used for wastewater treatment is the activated carbon. The exhausted activated carbon may either be disposed of by landfill or incineration, or otherwise may be regenerated. Regeneration is a commercially feasible and environmentally suitable preference. A number of regeneration methods including thermal [1], solvent [2], ultrasonic [3], and electrochemical regeneration [4] are available. Out of all these techniques, thermal regeneration is the most widely employed method of regeneration. However, thermal regeneration is a costly process due to high energy involved and also results in 5-10\% material losses [1]. The other regeneration methods have their own merits and demerits.

Electrochemical regeneration refers to the regeneration of exhausted adsorbent in an electrochemical cell. The regeneration involves the destruction of the adsorbed species and/or desorption from the surface and destruction into solution thereby restoring the original adsorption capacity of the adsorbent [5,6,7]. Above 90\% regeneration efficiencies have been reported for the electrochemical regeneration of activated carbon and therefore it is considered as an effective process [5]. The most important feature of electrochemical regeneration includes on-site destruction and removal of adsorbed contaminants. However, the high adsorption capacity and low electrical conductivity of activated carbon leads to longer regeneration times and therefore the process becomes costly. In addition, the electrochemical processes used for water treatment have high operating costs due to high cell voltages owing to low electrical conductivity of water.

In order to address these issues associated particularly with the electrochemical regeneration, an innovative and 
unique process was developed at University of the Manchester [8]. This process employs graphitic adsorbents for the adsorption of low concentrations of organic contaminants present in water followed by their electrochemical regeneration in a simple divided electrochemical cell $[9,10,11]$. In comparison to activated carbon, the graphitic adsorbent is non-porous and therefore acquires extremely low adsorption capacity. However, the adsorbent is capable of giving fast adsorption kinetics. The salient features of the graphitic adsorbents are their high electrical conductivity which has made them suitable materials to be commercially exploited for electrochemical regeneration purposes. The technique of employing graphite based adsorbents for adsorption and electrochemical regeneration in treating the low levels of organics in water is termed as Arvia ${ }^{\circledR}$ Process. The process can be operated in batch and in continuous mode $[9,10,11]$.

The process of adsorption with electrochemical regeneration using graphite based adsorbents is capable of reducing operating costs because of two factors. (i) since the mass transfer process occurs during the adsorption stage, therefore the mass transfer limitation is being eliminated in electrochemical processes involving low concentrations of organics and (ii) the relatively high electrical conductivity of graphitic adsorbents give low cell voltages. As stated earlier, two mechanisms of electrochemical regeneration of activated carbon has been recognized in literature [5], namely, the direct destruction of adsorbed contaminants onto the surface of GAC or desorption of adsorbed contaminants and their destruction in solution. In an ideal regeneration process, the adsorbed contaminants should be completely mineralized into carbon dioxide and water and therefore leaving no objectionable components into the solution. However, the generation of some of the intermediate oxidation byproducts may be possible depending upon the regeneration conditions. Previous studies have shown that intermediate oxidation products were formed during the electrochemical regeneration of a graphitic adsorbent loaded with phenol $[12,13]$. The main oxidation products detected include benzoquinone, hydroquinone, maleic and oxalic acid [7]. These studies have also shown that the intermediate oxidation by-products may be formed either due to the direct oxidation of adsorbed contaminants or by indirect oxidation of organics in solution, as shown in figure. The effect of a range of operating parameters including current density, $\mathrm{pH}$, electrolyte and initial concentration of the contaminant on the formation of breakdown products have indicated that the indirect electrochemical oxidation of organics in solution is the main mechanism responsible for the formation of breakdown products [8]. It was speculated that the graphitic adsorbents with high adsorption capacity would validate that this mechanism. Therefore, in the present paper, three adsorbents including graphite intercalation compound-bisulphate (GIC-bisulphate), recycled vein graphite (RVG) and expanded graphite (EG) were studied for the formation of intermediate oxidation by-products in a sequential batch electrochemical reactor. Phenol was selected as a model pollutant for adsorption and electrochemical regeneration studies using these materials.

\section{Materials and Methods}

\subsection{Materials}

The adsorbent materials, GIC-bisulphate, RVG and EG for the present study were provided by Arvia Technology Ltd UK. These were used as supplied without any treatment. The materials were characterized for their particle size using Laser size analyser, BET surface area by nitrogen adsorption technique, bulk density, surface morphology and bed electrical conductivity. These characteristics are provided in Table 1.

Table 1. Characterization of adsorbent materials [14]

\begin{tabular}{c|c|c|c|c}
\hline Adsorbent material & Particle size $(\boldsymbol{\mu m})$ & BET surface area $\left(\mathbf{m}^{\mathbf{2}} \mathbf{g}-\mathbf{1}\right)$ & Bulk density $\left(\mathbf{g c m}^{\mathbf{3}}\right)$ & Bed electrical conductivity $($ Scm \\
\hline GIC-bisulphate & 484 & 1 & 0.896 & Particle shape \\
\hline RVG & 436 & 1.54 & 0.96 & Flake \\
\hline EG & 784 & 17 & 0.225 & 1.4 \\
\hline
\end{tabular}

Analytical grades of all the chemicals including phenol, benzoquinone, 4-chlorphenol, oxalic acid, sodium chloride, hydrochloric acid were supplied by Sigma-Aldrich ${ }^{\circledR}$, UK.
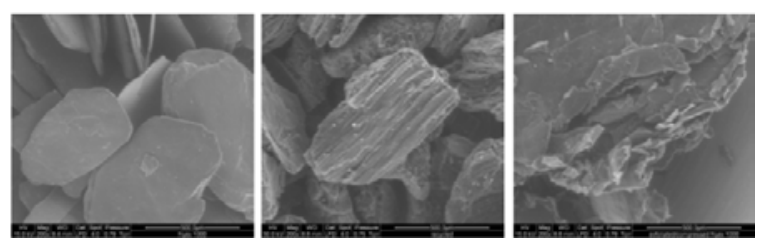

Figure 1. SEM images of GIC-bisulphate (left), RVG (middle) and EG (right) [14]

\subsection{Sequential Batch Electrochemical Reactor}

The batch electrochemical reactor shown in Figure 2 is used for carrying out the adsorption and electrochemical regeneration. It is a simple Y-shaped air agitated sequential batch reactor. The anode current feeder is a graphite plate $5 \mathrm{~mm}$ thick. The cathode is being made from stainless steel with $3 \mathrm{~mm}$ diameter perforations and with a thickness of $1 \mathrm{~mm}$. The area of each electrode is 50 $\mathrm{cm}^{2}$. The cell is divided into anode and cathode compartments by a microporous polyethylene, Daramic 350 separator (GraceGMBH). During the adsorption stage, air is being supplied through an array of orifices at the bottom of the cell using a compressor to carry out the mixing of the adsorbent particles with the contaminated water.

\subsection{Batch Adsorption and Electrochemical Regeneration}

A $500 \mathrm{~mL}$ of $100 \mathrm{mg} \mathrm{L}^{-1}$ of phenol solution was mixed with a fixed quantity of adsorbent in the batch electrochemical reactor, as shown in Figure 2, for $30 \mathrm{~min}$. 
This was the time required to achieve equilibrium during adsorption stage $[15,16]$. On the completion of adsorption, the air supply was turned off and the adsorbent particles were allowed to settle into the anodic section to form a particulate bed. Afterwards, a sample of the water present above the settled adsorbent was taken from the reactor and was analyzed for breakdown products as specified in the analysis section. The solution in the cathodic compartment was composed of $0.3 \% \mathrm{NaCl}$ in water acidified with $\mathrm{HCl}$ to a $\mathrm{pH}$ of $1-2$.

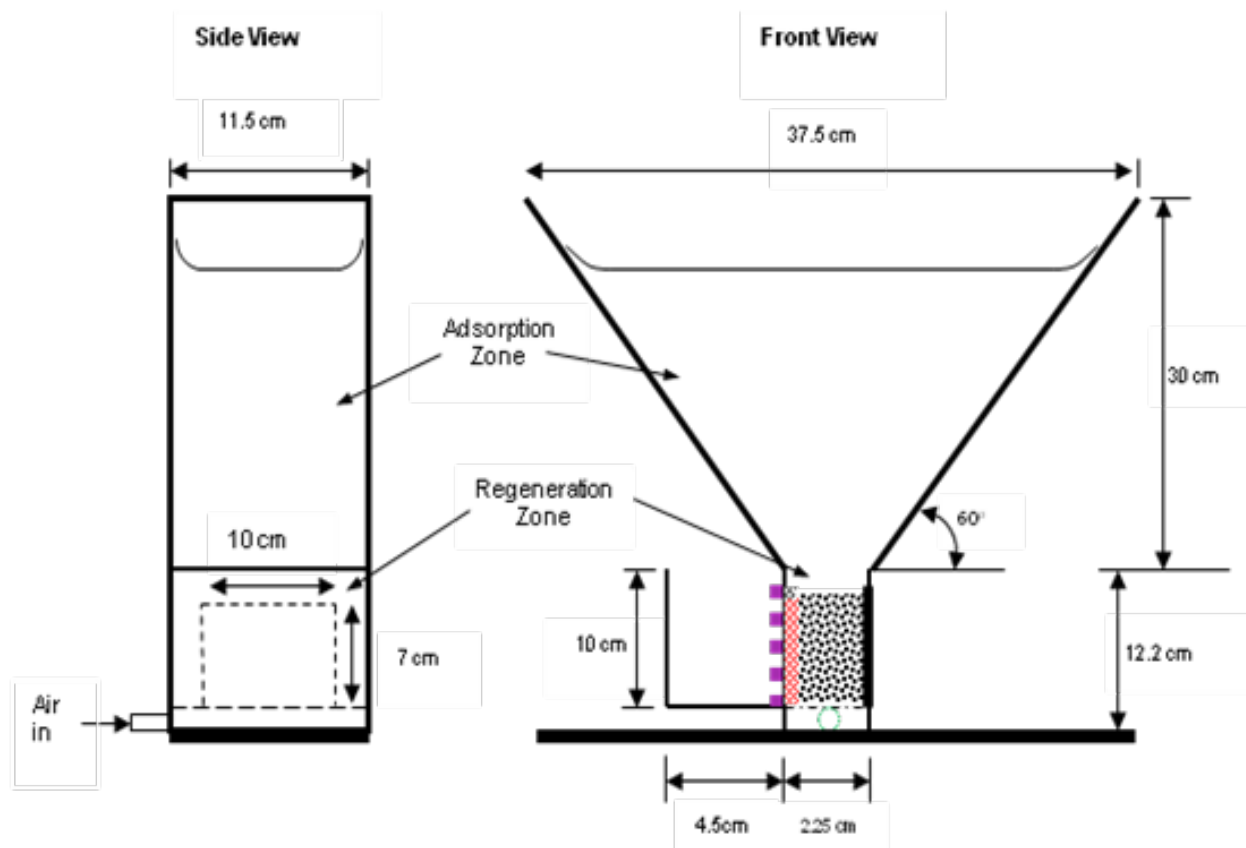

(a)

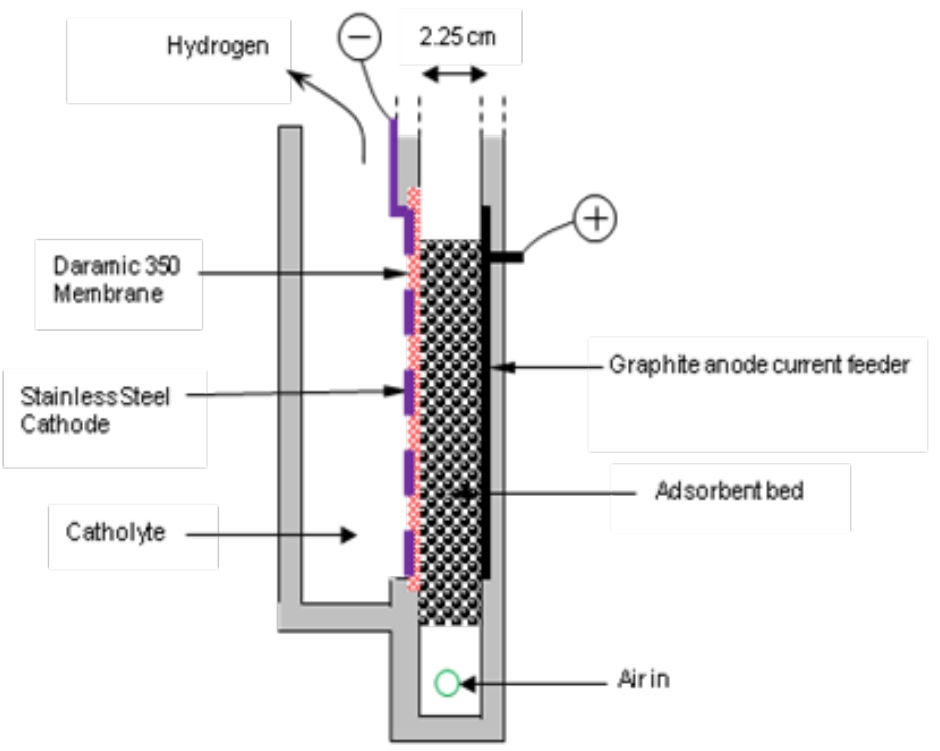

(b)

Figure 2. Schematic diagram of air agitated sequential batch reactor used for adsorption and electrochemical regeneration studies. (a) Schematic diagram showing side and front views of the mini-SBR, and (b) Schematic diagram showing a cross section of the electrochemical regeneration zone [13]

Electrochemical regeneration of the settled adsorbent bed was performed at $0.5 \mathrm{~A}$ for $20 \mathrm{~min}\left(10 \mathrm{~mA} \mathrm{~cm}{ }^{-2}\right)$. After the completion of the regeneration, the water was removed from the reactor. A sample of this water was also analyzed for breakdown products using the method as described in the analysis section. Phenol solution of the same concentration and same volume was added into the electrochemical reactor for second adsorption and then afterwards second regeneration. In this way, six adsorptions and five regenerations were carried out so as to count five adsorption and five regeneration cycles. Since, the first adsorption cycle completes after second adsorption. However, first regeneration cycle is completed after first regeneration. The entire experimental scheme was adopted for GIC-bisulphate, RVG and EG. 


\section{Analysis}

HPLC (Varian Prostar) equipped with a UV detector was used to analyze the aqueous samples for breakdown products collected after adsorption and electrochemical regeneration. The column, mobile phase and detection conditions for aromatics, aliphatic acids and chlorinated species are given in Table 2.

Table 2. HPLC conditions for the analysis of breakdown products including benzoquinone (BQ), oxalic acid (OA) and 4-chlorphenol (4-CP)

\begin{tabular}{|c|c|c|c|c|}
\hline Component & HPLC Column & Mobile phase & UV detection wavelength (nm) & Oven Temp $\left({ }^{\circ} \mathrm{C}\right)$ \\
\hline BQ & C-18 (Phenomenex) & $\begin{array}{l}50 \% \text { methanol solution in ultrapure water (0.7 } \\
\left.\mathrm{mL} \mathrm{min}^{-1}\right)\end{array}$ & 210 & 20 \\
\hline OA & Hi-Plex-H & $\begin{array}{l}0.1 \% \text { trifluoroacetic acid in ultrapure water } \\
\left(0.6 \mathrm{~mL} \mathrm{~min}^{-1}\right)\end{array}$ & 210 & 60 \\
\hline 4-CP & C-18 Phenomenex & $\begin{array}{l}\text { 45\% acetonitrile in ultrapure water containing } \\
\qquad 0.01 \mathrm{M} \mathrm{H}_{3} \mathrm{PO}_{4}\end{array}$ & 230 & 35 \\
\hline
\end{tabular}

In previous studies published on the formation of

\section{Results and Discussion}

A variety of by-products has been reported in the literature produced during the electrochemical oxidation of phenol in solution [17-21]. Comninellis \& Pulgarin [17] has suggested that electrochemically generated hydroxyl radicals are responsible for the electrochemical oxidation of organics on the surface of electrodes. These radicals are either physisorbed on non-active electrodes or chemisorbed on active electrodes. The complete degradation of the organics is possible on the non-active electrodes for example boron-doped diamond electrodes [19]. The GIC surface acted as non-active electrode due to the lack of breakdown products or another possibility could be the direct transfer of an electron to strongly adsorbed organics as suggested by [22]. The formation of some of the breakdown products during the electrochemical regeneration of graphite based adsorbents could be due to the following factors:

(i) The adsorbed organics onto the surface of the adsorbent get completely oxidised due to the transfer of electrons or by hydroxyl radicals (Figure 3).

(ii) The electrochemically produced hydroxyl radicals and other oxidants are responsible for the degradation of organics present in liquid phase which have not been adsorbed onto the surface. Due to an insufficient amount of the hydroxyl radicals generated in the electrochemical process the formation of some of the breakdown products could not be avoided (Figure 3). Mass transfer limitation is another important factor which could be the actual cause of incomplete oxidation especially when dealing with a low concentration of organics.

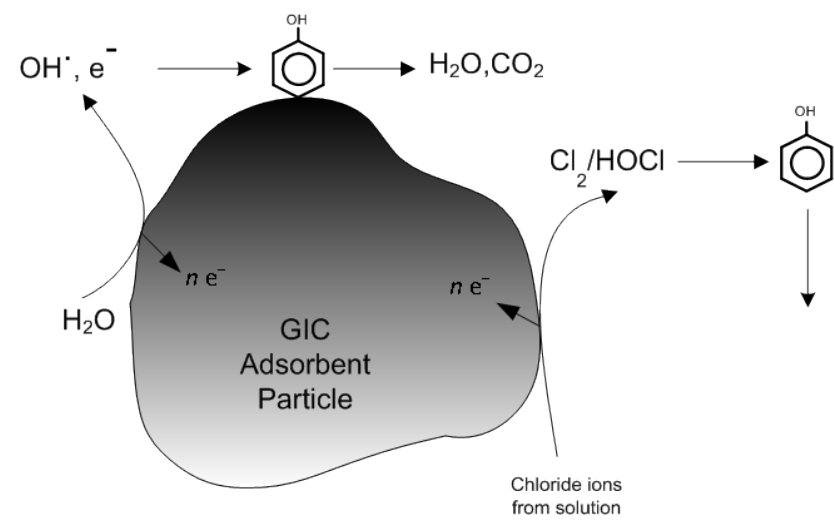

Figure 3. Schematic illustration of the complete degradation of adsorbed phenol and the formation of breakdown products due to indirect oxidation of dissolved phenol breakdown products during electrochemical regeneration of phenol loaded graphitic adsorbents, the main breakdown products observed were benzoquinone, hydroquinone, catechol, maleic and oxalic acid [12,13]. In addition, 2-chlorophenol and 4-chlorophenol were found as the main chlorinated breakdown species. Out of all the non-chlorinated products, the rate of degradation of benzoquinone was found to be lower in comparison to its rate of formation [12]. Therefore, among the nonchlorinated aromatic intermediates, the data regarding the trend of the formation of benzoquinone during adsorption and regeneration cycles have been provided for the three adsorbents, namely, GIC-bisulphate, RVG and EG (Figure 4). High concentrations of benzoquinone were found due to the electrochemical regeneration of phenol loaded GICbisulphate compared to the exfoliated graphite. However, there is not a significant difference in the concentration of benzoquinone observed during the adsorption and electrochemical regeneration cycles in the case of GICbisulphate and RVG during adsorption and regeneration cycles (Figure 4). Since the breakdown products are generated during electrochemical regeneration, therefore the concentrations of benzoquinone are relatively higher during regeneration cycles compared to adsorption cycles for all the adsorbents studied as shown in Figure 4.
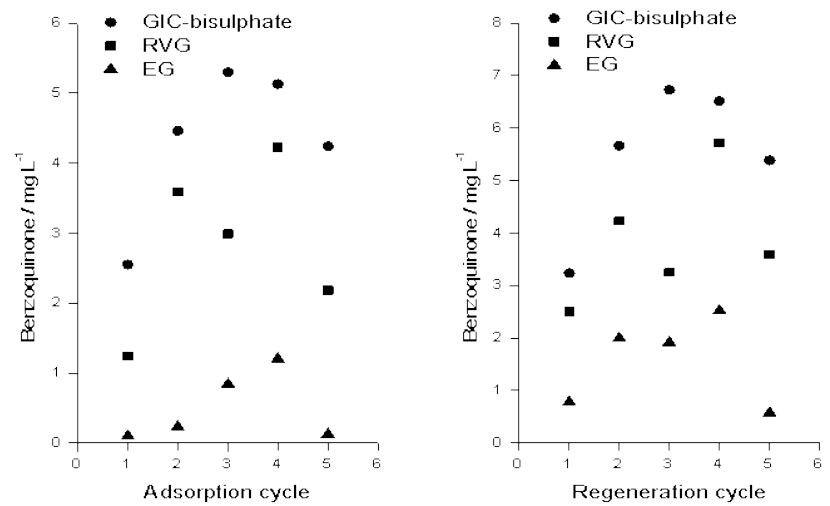

Figure 4. Formation of benzoquinone in solution after a series of adsorption and regeneration cycles cycles; Regeneration conditions for GIC-bisulphate and RVG: $0.5 \mathrm{~mA}$ current was passed through $10 \mathrm{~mm}$ deep bed for $20 \mathrm{~min}$ at a current density of $10 \mathrm{~mA} \mathrm{~cm}{ }^{-2}$; Regeneration conditions for expanded graphite: $0.5 \mathrm{~mA}$ current was passed through 10 $\mathrm{mm}$ deep bed for $40 \mathrm{~min}$ at a current density of $10 \mathrm{~mA} \mathrm{~cm}{ }^{-2}$ [14]

Phenol is first oxidised to quinonic species (cyclic intermediates) followed by the ring opening reaction forming organic acids which are ultimately converted into $\mathrm{CO}_{2}$ and $\mathrm{H}_{2} \mathrm{O}$. According to Tahar and Savall, [23] the degradation of para-benzoquinone can be considered as a 
rate limiting step in the electrochemical oxidation of phenol into aliphatic carboxylic acids. If this is true then at higher current density the comparatively high concentration of oxalic acid suggest that the degradation of phenol could be through the direct oxidation of phenol into carboxylic acids. It shows that phenol removal was more likely to be degraded to carboxylic acids at higher current density. Wu and Zhou [24] discussed similar findings for the partial electrolytic degradation of phenol to organic acids. In the present investigation, the trend of the formation of oxalic acid during adsorption and regeneration cycles for the three adsorbents has been shown in Figure 5. It can be clearly observed that relatively high concentrations of oxalic acid were formed in case of exfoliated graphite compared to GIC-bisulphate and RVG. The latter two adsorbents showed lesser concentrations of oxalic acid and with a similar variation during adsorption and regeneration cycles as shown in Figure 5. Based on these observations, it can be concluded that the electrochemical degradation of phenol at the surface of exfoliated graphite could be through the direct oxidation of phenol into carboxylic acids including oxalic acid.
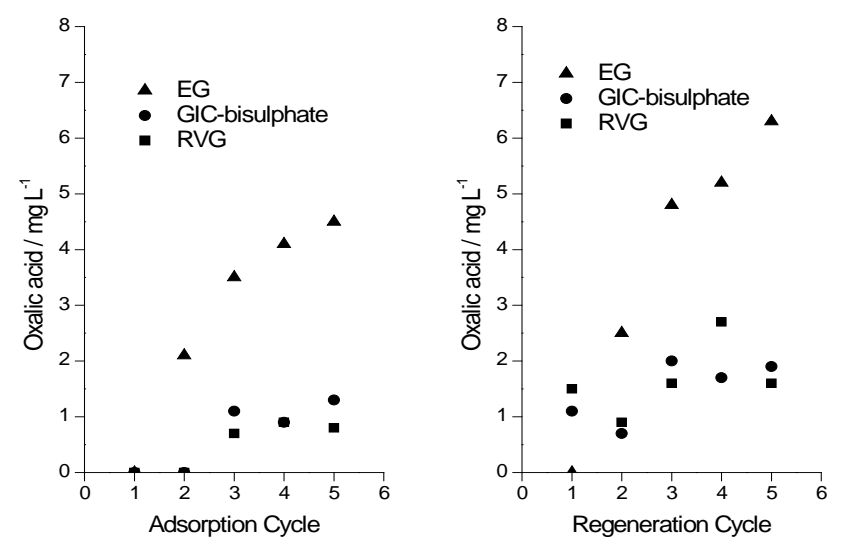

Figure 5. Formation of oxalic acid in solution after a series of adsorption and regeneration cycles cycles; Regeneration conditions for GICbisulphate and RVG: $0.5 \mathrm{~mA}$ current was passed through $10 \mathrm{~mm}$ deep bed for $20 \mathrm{~min}$ at a current density of $10 \mathrm{~mA} \mathrm{~cm}{ }^{-2}$; Regeneration conditions for expanded graphite: $0.5 \mathrm{~mA}$ current was passed through 10 $\mathrm{mm}$ deep bed for $40 \mathrm{~min}$ at a current density of $10 \mathrm{~mA} \mathrm{~cm}^{-2}$

As mentioned before that 2-chlorophenol and 4chlorphenol were observed as the main chlorinated species formed during the electrochemical regeneration of phenol loaded graphitic adsorbents [13], therefore, in the present investigation the formation of 4-chlorphenol only has been given (Figure 6). Figure 6 shows that higher concentrations of 4-chlorphenol were observed for GIC-bisulphate and RVG in comparison to exfoliated graphite. Fewer concentrations of 4-chlorphenol in case of exfoliated graphite could be attributed to the less amount of phenol present in solution during its electrochemical regeneration owing to the relatively high surface area of exfoliated graphite as shown in Table 1. It has already been shown that the main mechanism responsible for the formation of chlorinated breakdown products during electrochemical regeneration of phenol loaded graphitic adsorbent is the indirect oxidation of phenol present in solution during the electrochemical process [13]. Therefore, the low concentrations of 4-chlorphenol for exfoliated graphite further authenticates that chlorinated breakdown products are formed due to the indirect oxidation of phenol present in solution.
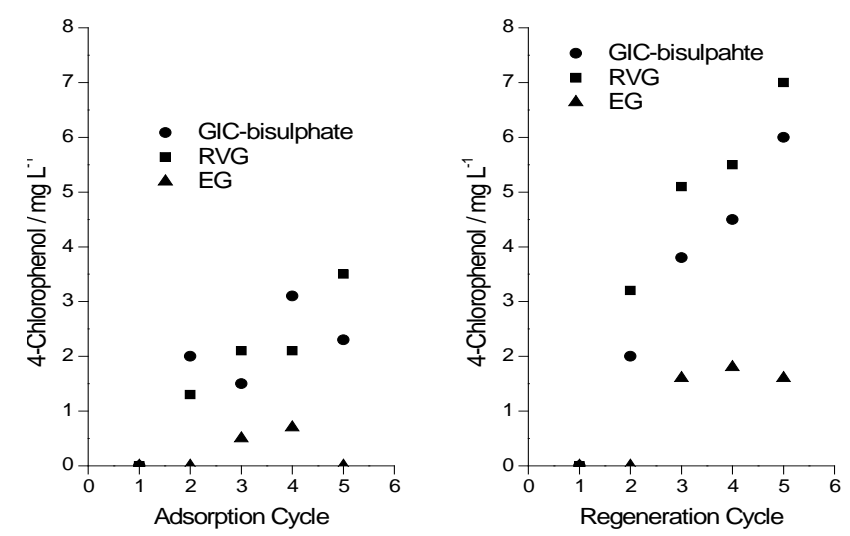

Figure 6. Formation of 4-chlorphenol in solution after a series of adsorption and regeneration cycles cycles; Regeneration conditions for GIC-bisulphate and RVG: $0.5 \mathrm{~mA}$ current was passed through $10 \mathrm{~mm}$ deep bed for $20 \mathrm{~min}$ at a current density of $10 \mathrm{~mA} \mathrm{~cm}{ }^{-2}$; Regeneration conditions for expanded graphite: $0.5 \mathrm{~mA}$ current was passed through 10 $\mathrm{mm}$ deep bed for $40 \mathrm{~min}$ at a current density of $10 \mathrm{~mA} \mathrm{~cm}{ }^{-2}$

Nevertheless, RVG has higher specific surface area and electrical conductivity compared to GIC-bisulphate as given in Table 1. Expanded graphite has the highest specific surface area in comparison to GIC-bisulphate and RVG. The high surface area of EG can be justified due to its rough surface morphology as evident in Figure 1. It is likely that more quantity of phenol was adsorbed per unit mass of the EG adsorbent. It was also speculated that the use of relatively high capacity adsorbents will minimize the formation of intermediate breakdown products. The higher quantity of phenol was adsorbed onto expanded graphite owing to its maximum surface area (See Table 1) leaving lesser amounts of the phenol in solution (data not shown). However, under the conditions of experiments, lesser quantities of aromatic breakdown products including benzoquinone and 4-chlorphenol were observed during regeneration of EG compared to the breakdown products formed in the case of GIC-bisulphate and RVG. Conversely, higher concentrations of carboxylic acids including oxalic acid were observed for EG compared to GIC-bisulphate and RVG. This shows that almost complete mineralization of the adsorbed phenol took place with negligible amount of indirect oxidation in solution in the case of EG. Thus, it can be concluded that the expanded graphite adsorbent can be effectively used for the commercial application of adsorption and electrochemical regeneration for wastewater treatment.

\section{Conclusions}

The present study has shown that less amounts of the breakdown products (in terms of benzoquinone and 4chlorphenol) were resulted due to electrochemical regeneration of phenol loaded expanded graphite in comparison to GIC-bisulphate and RVG. However, relatively high concentrations of oxalic acid were observed for exfoliated graphite compared to GICbisulphate and RVG. The present investigation reveals that the use of high capacity adsorbents, for example, exfoliated graphite with high electrical conductivity can be effectively regenerated in a simple batch electrochemical reactor without the formation of significant amounts of intermediate oxidation products. In addition, the use of relatively high capacity graphitic 
adsorbent proved to be helpful in authenticating the mechanism that the adsorbed species onto the surface of these adsorbents are completely mineralized to carbon dioxide and water leaving no or less intermediate products. Thus, the present investigation has important implications regarding the commercial application of adsorption using graphitic adsorbents and their electrochemical regeneration for wastewater treatment.

\section{Acknowledgements}

The authors would like to acknowledge the material support provided by Arvia Technology Ltd, UK. In addition, we are thankful to the University of the Punjab, Pakistan for its support for the project.

\section{References}

[1] Miguel, G.S., Lambert, S.D., and Graham, N.J.D., (2001). The regeneration of field-spent granular activated carbons. Water Research, 35(11), pp. 2740-2748.

[2] Sutikno, T., and Himmeistein, K.J., (1983). Desorption of phenol from activated carbon by solvent regeneration. Ind. Eng. Chem. Fundam, 22 (4), pp. 420-425.

[3] Lim, J.L and Okada, M., (2005). Regeneration of granular activated carbon using ultrasound. Ultrasonics Sonochemistry, 12, 277-282.

[4] Minghua, Z., Qizhou, D., Lecheng, L., and Dahui, W., (2005). Activated carbon adsorption- advanced electro-oxidative regeneration for the treatment of biorefractory organic pollutants. Chinese Science Bulletin, 50 (5), pp. 489-491.

[5] R.M. Narbaitz \& J. Cen (1994). Electrochemical regeneration of granular activated carbon. Water Research, Vol. 28 (8) pp. 17711778.

[6] Zhang, H., (2002). Regeneration of exhausted activated carbon by electrochemical method. Chemical Engineering Journal, 85, pp. 81-85.

[7] Karimi-Jashni, A., and Narbaitz, R.M., (2005). Electrochemical Reactivation of granular activated carbon: effect of electrolyte mixing. Journal of Environmental Engineering, 131 (3), pp. 443449.

[8] Eccleston, K.T., Eccleston, A.J., Richards, J.L., Brown, N.W., and Roberts, E.P.L., (2010). Apparatus for the electrochemical regeneration of adsorbents. US Patent 7790024 B2.

[9] Eccleston, K.T., Brown, N.W., Roberts, E.P.L., and Richards, J.L., (2009). Adsorbents for treating contaminated liquids. US Patent 2009/0321361 A1.

[10] Brown, N.W., Roberts, E.P.L., Garforth, A.A., and Dryfe, R.A.W., (2004a). Electrochemical regeneration of a carbon-based adsorbent loaded with crystal violet dye. Electrochimica Acta, 49 (20), pp. 3269-3281.

[11] Brown, N.W., Roberts, E.P.L., Chasiotis, A., Cherdron, T., and Sanghrajka, N., (2004b). Atrazine removal using adsorption and electrochemical regeneration. Water Research, 38 (13), pp. 30673074.

[12] S.N. Hussain, E.P.L. Roberts, H.M.A. Asghar, A.K. Campen \& N.W. Brown (2013) Oxidation of phenol and adsorption of breakdown products using a graphite adsorbent with electrochemical regeneration. Electrochimica acta, Vol. 92 pp.2030.

[13] S.N. Hussain, H.M.A. Asghar, A.K. Campen, N.W. Brown \& E.P.L. Roberts (2013) Break down products formed due to oxidation of adsorbed phenol by electrochemical regeneration of a graphite adsorbent. Electrochimica acta, 110, 550-559.

[14] S. N. Hussain, H. M. A. Asghar, H. Sattar, N. W. Brown, and E. P. L. Roberts, Formation of by-products during electrochemical regeneration of various graphitic adsorbents in a batch electrochemical reactor. International Journal of Chemical, Biomolecular, Metallurgical, Materials Science and Engineering Vol: 7 No:9, 2013, pp. 338-341.

[15] H.M.A. Asghar, E.P.L. Roberts, S.N. Hussain, A.K. Campen \& N.W. Brown (2012) Wastewater treatment using adsorption and electrochemical regeneration using graphite based adsorbents. Journal of applied electrochemistry, Vol. 42(9) pp. 797-807.

[16] H.M.A. Asghar, S.N. Hussain, E.P.L. Roberts, A.K. Campen \& N.W. Brown (2013) Pre-treatment of adsorbents for wastewater treatment using adsorption coupled with electrochemical regeneration. Journal of Industrial and Engineering Chemistry, 19,1689-1696.

[17] Sharifian, H., and Kirk, D.W., (1986). Electrochemical oxidation of phenol. J. Electrochem. Soc, 133(5), pp. 921-924.

[18] Comninellis, C., and Pulgarin, C., (1991). Anodic oxidation of phenol for wastewater treatment. Journal of Applied Electrochemistry, 21, pp. 703-708.

[19] Iniesta, J., Michaud, M.A., Panizza, M., Cerisola, G., Aldaz, A., and Comninellis, C., (2001). Electrochemical oxidation of phenol at boron-doped diamond electrode. Electrochimica Acta, 46, pp. 3573-3578.

[20] Gattrell, M., and Kirk, D.W., (1990). The electrochemical oxidation of aqueous phenol at a glassy carbon electrode. Can. J. Chem. Eng, 68, pp. 997-1003.

[21] Comninellis, C., and Pulgarin, C., (1993). Electrochemical oxidation of phenol for wastewater treatment using $\mathrm{SnO}_{2}$ anodes. Journal of Applied Electrochemistry, 23, pp. 108-112.

[22] Brown, N.W., and Roberts, E.P.L., (2007). Electrochemical pretreatment of effluents containing chlorinated compounds using an adsorbent. Journal of Applied Electrochemistry, 37 (11), pp. 13291335.

[23] Tahar, N.B., and Savall, A., (1998). Mechanistic aspects of phenol electrochemical degradation by oxidation on a $\mathrm{Ta} / \mathrm{PbO}_{2}$ anode. $J$. Electrochem. Soc, 145(10), pp. 3427-3434.

[24] Wu, Z., and Zhou, M., (2001). Partial degradation of phenol by advanced electrochemical oxidation process. Environ. Sci. Technol, 35, pp. 2698-2703. 